\title{
A Sexually and Physically Abused Child: His Inner World
}

Carmen Mayugba-Sugai, M.D.

Tulane Medical Center, New Orleans, Louisiana

Follow this and additional works at: https://jdc.jefferson.edu/jeffjpsychiatry

Part of the Psychiatry Commons

Let us know how access to this document benefits you

\section{Recommended Citation}

Mayugba-Sugai, M.D., Carmen (1990) "A Sexually and Physically Abused Child: His Inner World," Jefferson Journal of Psychiatry. Vol. 8 : Iss. 2 , Article 6.

DOI: https://doi.org/10.29046/JJP.008.2.003

Available at: https://jdc.jefferson.edu/jeffjpsychiatry/vol8/iss2/6

This Article is brought to you for free and open access by the Jefferson Digital Commons. The Jefferson Digital Commons is a service of Thomas Jefferson University's Center for Teaching and Learning (CTL). The Commons is a showcase for Jefferson books and journals, peer-reviewed scholarly publications, unique historical collections from the University archives, and teaching tools. The Jefferson Digital Commons allows researchers and interested readers anywhere in the world to learn about and keep up to date with Jefferson scholarship. This article has been accepted for inclusion in Jefferson Journal of Psychiatry by an authorized administrator of the Jefferson Digital Commons. For more information, please contact: JeffersonDigitalCommons@jefferson.edu. 


\title{
A Sexually and Physically Abused Child: His Inner World
}

\author{
Carmen Mayugba-Sugai, M.D.
}

\begin{abstract}
This paper describes how a sexually abused 8 year old boy's internal dynamics correlated with and influenced his behavior while he was on an inpatient unit. Through play therapy and unit staff's observation, the psychopathological sequelae to the abuse unfolded in a very interesting way. This process of correlating play material with observations of behavior on the unit, helped the treatment team in understanding the child's inner world.
\end{abstract}

\section{INTRODUCTION}

The outcome of sexual and physical abuse on a child's psychological and developmental life has been documented in the child abuse literature $(1,2)$. Descriptions of therapeutic interventions ranging from family work and environmental change to group and individual therapy have also been cited $(3,4,5,6)$. The literature has also elaborated on an individual therapy approach (1) aimed at utilizing specific psycho-therapeutic interventions to deal with major psychopathological sequelae to abuse such as; acute traumatic reactions, impairment of ego functions, distortion of object relations, poor impulse control, poor selfconcept and school difficulties. John Weil's recent clinical case studies $(7,8)$ focus on the symptoms and dream content of children who had been exposed to various types of instinctual (erogenous, erotic punitive) stimulation by adults. However, there seems to be a paucity of literature describing specific treatment cases; particularly cases that focus on the behavior of the abused child as it correlates with his or her inner mental life as portrayed by the themes of play. The study conducted by Weil $(7,8)$ is probably one of the few works on the subject which focuses on specific case studies (100 cases) presenting the correlation of erotic and punitive stimulation with symptom formation and dream profile.

This paper presents the clinical case of a boy who had been physically and sexually abused. The case lends itself to a systematic review similar to that of Dr. Weil $(7,8)$. In this paper behavioral symptoms are correlated with play therapy

Address correspondence to Dr. Mayugba-Sugai, 26 Terraza del Este, Harvey, LA 70058 
themes. In Weil's case studies, the sources of erotic and punitive stimulation are correlated with the behavioral symptoms and dream content. The play themes described here represent the child's inner mental life just like the dream profiles represented the inner mental life in J. Weil's cases. The process of correlating the behavioral symptoms as observed on the inpatient unit with the play therapy themes, provided an opportunity to integrate the child's internal psychodynamics with his behavior which in turn helped the treatment team in the management and therapy of the child. For the purpose of protecting the child's identity, his name has been changed in this presentation.

\section{CASE STUDY}

Bobby is an eight year old boy who had been raised in a chaotic home environment where there was parental discord and violence. Bobby would often be the victim of either one or sometimes both parents' physical violence. By the time Bobby was four years old, the parents had divorced. Bobby was left in the custody of his biological mother. A series of mother's boyfriends soon became part of Bobby's world. Meanwhile, the biological mother's erratic and unpredictable lifestyle led Bobby to fend for himself most of the time. When Bobby was about $6 \frac{1}{2}$ years old, one of his mother's boyfriends sexually molested him. His mother ignored and refused to act on Bobby's allegations. It was Bobby who eventually called the police for help. Child Protective Services subsequently took custody over Bobby. He was first placed in a foster home where he acted out a great deal-i.e. was physically aggressive toward the other children in the home, oppositional toward his foster parents, and sexually stimulated the other children in the home. While at this foster home, he was physically beaten by the foster father. He was taken out of this foster home and there subsequently followed two group home placements prior to his eventual hospitalization. At both group home placements he had exhibited the same behavioral problems. He had also included self-destructive behavior in his repertoire of symptoms, especially at the group home prior to his admission to the hospital. It was these persistent behavioral difficulties that eventually brought him to the hospital.

Bobby presented himself as an intelligent and engaging eight year old. He looked younger and smaller than his stated age, although he acted and talked like he was older. His reality testing was intact but he was highly anxious. He moved into the use of toys and play rather quickly and seemed eager to express feelings and experiences through the play metaphor. He displayed a need to control people and situations around him such that at times he came across as "bossy." His need to be liked by others was gleaned by his attempts to play the "good child" role, a role which would be quickly reversed to the "bad child" role at the slightest perception of rejection from others. Sometimes this "bad child" surfaced on occasions when he would set himself up for consequences resulting from transgressions of some unit rule. It was also interesting that within the 
milieu, his behavior varied depending on the issues or conflicts he was working on in individual therapy, or vice versa.

The inpatient unit where Bobby stayed for six months is an 8-bed latencyage group unit where the emphasis is on the provision of firm limit setting within a warm and nurturing environment. Behavioral therapy, special education, therapeutic milieu, individual play therapy and pharmacotherapy are the therapeutic modalities utilized in the management and care of the children. Bobby was seen in individual play therapy about three times a week. At the weekly staff meetings, observations regarding his behavior on the unit and the play themes noted at individual therapy were shared among the treatment team members. Throughout the hospitalization, Bobby did not receive any medications.

Following, is a discussion of the common themes of his play and descriptions of his behavior on the unit. These observations date from the time of admission to the time of discharge. The unit staff maintained a log book of the child's behavior on the unit during the different activities throughout the day. The play themes presented were from the compiled notes of the play sessions. The discussion of the treatment course is divided up into arbitrary time frames based on either a perceived movement in the treatment or a change in the themes in his play.

\section{First Three Weeks}

On the unit, Bobby was oppositional, verbally and physically threatening toward peers and staff. He also exhibited sexual overtures toward peers. He had nocturnal enuresis about 3-5 times per week. He displayed an increased need for attention as well as a compulsion to control people and situations around him. He had difficulty at school as shown by his poor concentration and sometimes he refused to do the work in class. The first 3 weeks were the most difficult times for both the patient and the staff. Room restrictions had to be imposed to contain his aggressive and disruptive behavior on the unit.

In play therapy, themes of aggression and sexuality were played out; men shooting each other, animals and men kicking others from behind. He described occasions when he was physically beaten by adults (biological parents, foster father). He shared experiences where his biological mother had left him to fend for himself, i.e. cook his own meal because his mother was not home. He brought his own stuffed animals with him to the sessions. He used these stuffed animals to express some feelings and needs. The animals would feel "angry, sad." The animals were given solicitous attention during feeding time and at bedtime. At the end of the sessions, he would hide some of the toys in the office and sometimes he would request that he be allowed to take the toys with him back to the unit. Bobby also liked to play "hide and go seek" games with the therapist while on the way back to the unit. 


\section{The Fourth Week}

On the unit, Bobby continued to have oppositional behavior. The sexual overtures and threatening behavior toward peers were decreased, however. $\mathrm{He}$ displayed an increased need for attention from the staff. He started to earn points at school as he began to get settled in the school routine. He also started to earn points on the unit as he showed some amount of cooperation and compliance with the treatment program. There was no need for room restriction on this particular weekend unlike the previous three weekends.

In play therapy, he repeatedly constructed a wall around a dollhouse and then proceeded to break the walls apart. Sometimes he would put bombs inside the house or around the walls. The bombs would then explode and the whole structure would be torn apart in chaos and destruction. At one point, he left the bombs on the office walls. When he returned for his next session, the bombs were taken off the wall and he was told that the bombs had been defused. He then proceeded to play out a game where he was back in the house with his mother and there were 10 bombs inside the house, 7 of which, he defused. Later, in the session, he shared other experiences where his biological parents had physically abused him. During this week, he was not bringing his toys into the office anymore, nor was he asking to keep some of the office toys. His "hide and go seek games" had stopped.

\section{Fifth to the Seventh Week}

On the Unit, there was a marked decrease in his oppositional behavior as well as in his sexual overtures. The enuresis had decreased to about 2-3 times a week. He showed better school performance. He continued to need a lot of attention and nurturing from the staff.

In play therapy, themes of aggression continued to be played out; Rambo killing an entire army. He used finger paint in a very disorganized and messy way, purposely leaving some paint marks on the walls and carpet. He also continued to construct walls around the dollhouse. However, this time, attempts to break the walls apart were less successful. He also showed less intensity and impetus to destroy or break down the walls. He shared more experiences regarding physical and sexual abuse, but this time he showed a much more appropriate affect as he talked about the painful experiences. He used the puppets to express his feelings of sadness and wanting to be cared for; "Little bunny wants to go home and be cared for by his own mother."

\section{Eighth to Ninth Week}

On the unit, Bobby continued to display persistent oppositional behavior. He could, however, be easily redirected. He was persistently needy, especially around homework time, requiring 1:1 attention from staff. There were no sexual overtures at this time. 
In play therapy, the theme of good vs. bad was played out repeatedly; Rambo was the good guy who rescued a family from the hands of a bad guy. Bobby also played out a scene where Rambo balanced on a tight rope together with the bad guy. The bad guy fell over several times whereas Rambo only slipped off two times without ever really falling over.

\section{Tenth to the Fourteenth Week}

On the unit, Bobby resorted to an increase in his oppositional and aggressive behavior following a cancelled play therapy session. He reacted to this missed session with verbalizations of "I am no good" and his behavior escalated to the point where a room restriction had to be imposed. On subsequent days, however, his behavior improved. There was still a tendency to set himself up for consequences, i.e. lying, cheating, not doing homework. At this time too, plans for discharge were being made in collaboration with the case social worker. A therapeutic foster family was the intended after-care plan. The possibility of the biological mother's continuing role in long-term plans; such as visitation privileges while Bobby was in foster care, was likewise being assessed at this time. Bobby's behavior was marked by increased need for nurturance, especially around the weekends when he saw other children leaving for weekend passes with their parents. There was some sexual acting-out mostly in the form of showing his body to other peers. Enuresis occurred about 2-3 times a week.

In play therapy, the day after missed therapy session, he acted out a puppet show with themes of "eating up," and retaliation or getting-even. In his play, a hungry alligator dragged the caretaker to his death because the caretaker had forgotten to feed the alligator. He also spoke about his fantasies of being reunited with his mother. While talking about being reunited with his biological mother, he played out a reunion scene between a baby kangaroo and a mother kangaroo. Apparently, the mother kangaroo had been away, and in her absence, other animals had taken care of the baby kangaroo. At the reunion with the mother kangaroo, the other animals looked on quite anxiously; afraid that the mother kangaroo might give "germs" to the baby kangaroo.

\section{Fifteenth to Seventeenth Week}

On the unit, supervised visits with the biological mother were arranged. Bobby's ambivalence toward his biological mother was expressed in several ways: he spoke directly about "not deserving to see his mom" shortly after he had clogged the toilet; he had an episode of sexually acting-out before the visit; following the supervised visit with his biological mother he stabbed a picture he had drawn of a witch. His oppositional behavior on the unit was also such that he needed much redirection from the staff. His enuresis persisted about 2-3 times a week. 
In play therapy, his ambivalent feelings toward his biological mother were manifested in the following ways: 1. A story where a family was intruded upon and the good guys saved them. The little boy in the family goes to the restroom and emits a foul odor, causing his mother and father to faint. 2. Another story where a boy gets reunited with the rest of his family, presenting "surprise gifts" to everyone. In the end however, the boy was left behind again by himself. 3 . He verbalized fears that his biological mother may not be able to make it for the visit, "She may have a flat tire."

\section{Eighteenth to Twentieth Week}

As finalization of discharge plans was underway, a disorganization of Bobby's behavior occurred on the unit resulted. Thereafter, he was more subdued but still required extra attention from the staff. At this point, the after care plan was for Bobby to stay with the new foster family that the social worker had arranged. The biological mother would be granted only supervised visits with Bobby. He was well aware of these plans and appeared to concede to them. At this time, his enuresis occurred only about $1-2$ times a week.

In play therapy, in the beginning of the week, his play was disorganized-he shifted from one activity to the next making little sense. He also re-enacted the sexual abuse scenario using cowboys to depict it. He spoke about a dream where his biological mother was swimming and was attacked by a shark and an octopus. His biological mother was dismembered and mutilated, while he looked on helplessly. He also verbalized feeling angry at his biological mother while at the same time feeling sad because he couldn't be with her. He continued to play out the theme of good vs. bad, but this time acknowled that the two contrasting attributes can co-exist in the same play character. The stories he played out also depicted his struggle at trying to feel good about himself in the midst of his angry feelings.

\section{Twenty-first to Twenty-fourth Week}

Two significant changes occurred during this time frame: (1) change of therapist, and (2) biological mother underwent surgery. His behavior on the unit was marked by increased oppositionalism and angry mood. He also had the flu at this time, and appeared to enjoy the "sick role" for a while as his nurturant needs were met. When his biological mother recovered from surgery, there was a marked improvement in his behavior for about a week. Meanwhile, preparations for short passes with the new foster parents were being arranged. The fact that he was not going home to his biological mother cast its full impact on Bobby at this time. His behavior temporarily regressed to earlier levels; -oppositional, disruptive, difficult at school, sexually acting-out and threatening behavior toward peers. Although he manifested all the above negative behaviors, he was still able to respond to redirection, limit-setting and structure. After the passes 
with the foster parents he came back to the unit cheerful, agreeable and manageable. During this difficult transition, he was not having as many problems with enuresis; having only 2 episodes of enuresis and 28 nights free of enuresis.

In play therapy, sessions were replete with punitive and aggressive themes. He was more verbal in expressing his thoughts and feelings. He talked quite openly about anxieties regarding the new foster home; will they be good to him, take care of him, will he still see his biological mother? At the same time, he worked on terminating with the treatment team and milieu. He played out good-bye scenes with the puppets; expressing feelings of sadness at leaving a familiar setting, coupled with feelings of expectant anticipation for a new chance with this new set of foster parents. Being able to continue supervised visitations with his biological mother also made him look forward to discharge.

Throughout the above discussion, the play themes and even some playacting scenes have been elaborated upon. For children under the age of 12 years, playing is a natural medium of communication and therapists encourage the child to play through the use of paintings, drawing, toys, dolls, etc. The child uses play both, as a way of externalizing mental experiences, and as a means of abreaction and mastery. In treatment, play is regarded as an unconsciously determined communication influenced by the presence of a therapist (9). Likewise, play is viewed as a bridge between unconscious fantasy and external reality, offering the therapist the opportunity to gain access to the child's inner thoughts and preoccupations (10). Non-directive play therapy also provides an opportunity for the child to experience growth under the most favorable conditions. Since play is the child's natural medium of self-expression, the child is given the opportunity to play out his accumulated feelings of tension, frustration, insecurity, aggression, fear, bewilderment, and confusion (11). It was in the above context of understanding that Bobby's play themes have been viewed.

\section{FORMULATION}

The symbolic re-enactment of the sexual and physical abuse was necessary and occurred early on in treatment. The psychically traumatized child automatically attempts to employ play in order to cope with the traumatic anxiety that has overwhelmed him or her. The child's trauma could be retrospectively understood by looking at the components of the child's play (12). In Bobby's case, the sexual abuse was gleaned as he played out with dolls and animals the trauma inflicted on him. Similarly, the physical abuse was played out with dolls attacking each other, or with the dolls being thrown up in the air, of animals being wrapped up in plastic tapes and in play-acting where he wrapped some of his body parts (arms and legs) with plastic tapes. Aside from playing, Bobby was also able to talk directly about some of the physical beatings he had received from his biological parents and former foster home parent (foster parent \#1). The reenactments of the abuse also recurred when prospects for another foster care placement (Foster parent \#2) was being planned for. The anxiety in anticipation 
of placement may have reawakened fears of possible repeated abuse at the hands of other adults. His play themes of "eating up" and the story of the hungry alligator who got even with his caretaker, could be viewed as; themes of oral aggression fueled by feelings of deprivation coupled with, angry feelings towards the negligent need-satisfying adult caretaker.

The difficult times when Bobby's behavior required room restriction to contain his aggressive and disruptive behavior on the unit could be understood in the context of his sense of "being a bad boy." The sense of badness could well have been borne from his past experiences of abuse and rejection. This sense of badness pervaded much of his oppositional behavior during his hospital stay. There were fluctuations in his oppositionalism, with a tendency to get worse under certain circumstances, namely: (1) perceived rejection (examplecancelled play session); (2) fear of being abandoned (examples-mother's surgery, change of therapist); (3) in response to anxiety (example-anticipation of foster home placement). Coinciding with the above behavior, his play themes revolved around the issue of good vs. bad as well as around themes of retaliation.

The sense of unpredictability in his past external environment, and his own internal chaos were portrayed in his play by his repeatedly constructing walls which was followed by their inevitable destruction (see 4 th week). It seemed that once he was allowed a chance to prevent total destruction from happening symbolically in the play setting, he gained some sense of control, a feeling contrary to the helplessness engendered by the inevitable destruction. It was interesting to note that after having re-enacted these themes, there followed an improvement in his overall behavior, with him becoming more accessible to limit setting. He likewise developed a sense of "settling down" on the unit at this point.

The impairment of his object relations was likewise notable. His mistrust in and testing of the milieu contributed to his initial oppositionalism. As he developed an alliance with staff, his disruptiveness became much more manageable. At the first session, he brought his stuffed animals which he used to express his feelings of uncertainty about being "cared for." Testing of the therapist's interest in him was carried out by his hide and seek behavior. His tendency to ask for the therapist's toys was indicative of his poorly developed object-constancy. He required token symbols of the therapist so that he could maintain an inner representation of the therapist during the brief separation between sessions.

In response to perceived rejection, he attributed badness to himself which in turn led to provocative behavior resulting in consequences. At that point, he turned that badness out to the staff. The staff now became the "bad parent" to him. This mechanism was prevalent around the time supervised visits with biological mother were underway. It seemed that he needed to preserve the fantasy of a "good mother" and he accomplished this by viewing the unit staff as the "bad parents" who set limits and consequences to his disruptive behavior. While doing this, he simultaneously expressed ambivalent feelings toward his biological mother as gleaned from; his verbalizations, his dream of mother being 
dismembered by the shark and octopus, and his play of the baby kangaroo's reunion with the mother kangaroo. The supervised visits with the biological mother provided an opportunity for Bobby to work through his ambivalence.

\section{OUTCOME OF TREATMENT}

Over the course of six months, some of the gains of his hospitalization were:

1. Reaching a point where he could respond more positively to redirections and limit setting. There was less tendency to view limitsetting from adults as a punitive act. Coupled with this development is the improved sense of self so that he did not have to see himself as "all bad" when limits were set on his behavior.

2. Underneath this facade of the "difficult, bad child" was a deeply needy child who devoured attention and nurturance whenever these were made available to him. After he had abreacted the traumatic episodes in his life, this neediness became more apparent. He was later able to verbalize and express his needs more directly rather than act them out in disruptive and aggressive ways.

3. Towards the time of discharge, he was capable of expressing his feeling states more directly without resorting to acting-out behavior. There was a greater tolerance for frustration and for separation.

4. As his anxiety level decreased, he demonstrated a better school performance as well as better participation in unit activities. He showed good academic performance at the times when he was most subdued and calm. On the unit, he showed some leadership abilities and got along well with his peers during these periods of calm.

5. The frequency of enuresis had diminished over time, that is, from 3-5 times a week in the beginning to about 1-2 times per week by the 20th week. Also during the month of discharge, it was noted that he had only 2 episodes of enuresis and 28 days of being dry at night. It is worth mentioning that the monitoring of the enuresis may not have been as well supervised as would have been intended.

\section{CONCLUSION}

In the treatment of this sexually and physically abused child, the integration and correlation of his behavior with his inner mental life, as inferred from his play themes, was the key to working with him. The disturbed, disruptive child on the unit was seen in play sessions as an imaginative child who tried to work out his conflicting feelings, fears and wishes in symbolic play. The treatment team worked together through the exchange of observations which in turn led to a broader and more comprehensive understanding of the child.

Labeling of the child's behavior was replaced by the search for meanings behind the behavior. In this search for meaning, the play material often times 
became the source for some answers and sometimes some direction in the treatment approach. The child's oppositional and aggressive behavior correlated with his play themes of aggression and sexuality as he tried to work out the angry feelings related to the sexual and physical abuse. The oppositional behavior was also understood in the context of feelings of rejection, fear of abandonment, anticipatory anxiety and feelings of ambivalence. His underlying mistrust of the adults and of the environment were gleaned from his testing and oppositional behavior, as well as from his play of repeated building and destruction. Equipped with these insights, the treatment team was more able to respond to Bobby's needs and demands. Interventions were guided by these insights as well.

This case study provided an opportunity to present a systematic review of a child who had been abused physically and sexually. This case study further supports that clinical cases can lend themselves for good systematic review of historical data and treatment.

\section{REFERENCES}

1. Green AH: Psychopathology of Abused Children. Journal of the American Academy of Child Psychiatry 17:92-103, 1978

2. McLeer SV, Deblinger E, Atkins MS, Foa EB, Ralph DI: Post-Traumatic Stress disorder in Sexually Abused Children. Journal of the American Academy of Child Psychiatry 27:650-654, 1988

3. Green AH: Psychiatric Treatment of Abused Children. Journal of the American Academy of Child Psychiatry 17:356-371, 1978

4. Jones DPH: Individual Psychotherapy for the Sexually Abused Child, In Child Abuse and Neglect, vol. 10, 377-385, 1986

5. Berliner L and Ernst E: Group Work with Preadolescent Sexual Assault Victims, In Victims of Sexual Aggression: Treatment of Children, Women and Men, IR Stuart and LG Greer (Eds), Van Nostrand Reinhold, New York, 1984

6. Jones DPH and Alexander H: Treating the Abusive Family within the System, In The Battered Child, 4th ed., RF Helfer and RS Kempe (eds.) University of Chicago Press, Chicago

7. Weil J: Instinctual Stimulation of Children: From Common Practice to Child Abuse, vol 1. International Universities Press, Connecticut, 1989

8. Weil J: Instinctual Stimulation of Children: From Common Practice to Child Abuse, vol 2. International Universities Press, Connecticut, 1989

9. Feigelson CI: On the Essential Features of Child Analysis. Psychoanalytic Study of the Child. 32:353-362, 1977

10. Hoxter S: Play and Communication, In The Child Psychotherapist and Problems of Young People. Mildwood House, London, 1977

11. Axline V: Play Therapy, 1969 ed. Ballantine Books

12. Terr LC: Forbidden Games: Post-Traumatic Child's Play. Journal of the American Academy of Psychiatry. 20:741-760, 1981 